Praxis : Jurnal Sains, Teknologi, Masyarakat dan Jejaring | Vol. 3 | No. 2 | Maret 2021

\title{
Pengukuran Mutu Layanan Dan Kepuasan Nasabah Pada PT (PERSERO) Bank Bri Klaten Kantor Kas UNWIDHA
}

\author{
Arif Julianto Sri Nugroho; Abdul Haris; Agung Nugroho Jati; Anis Marjukah; \\ Purwo Haryono; Dandang Setyawanti; Tasari \\ Universitas Widya Dharma Klaten \\ email: arifjuliantosn72@gmail.com
}

\begin{abstract}
Abstrak
Penelitian ini bertujuan menguji kepuasan layanan pada institusi keuangan publik PT Bank BRI (Persero) Kantor Kas Unwidha Klaten melalui uji kesenjangan antara harapan mutu layanan dan persepsi nasabah terhadap mutu layanan yang telah diberikan. Metode riset yang dilakukan melalui uji kuantitatif sampel sebagai responden sebanyak 104 nasabah melalui teknik pengambilan sampel secara Convenience. Uji kuantitatif dilakukan dalam penelitian meliputi uji validitas, uji reliabilitas butir kuesioner dan uji konfirmasi servqual. Hasil riset menjelaskan bahwa semua dimensi dalam Servqual meliputi bukti fisik, reliabilitas, jaminan, daya tanggap dan empati kesemuanya masih memiliki nilai kesenjangan dengan nilai rerata -57.27 poin, yang berarti belum memuaskan nasabah. Dimensi reliabilitas dari uji kuantitatif memiliki nilai kesenjangan terbesar senilai -65.50 poin sehingga harus menjadi prioritas PT Bank BRI dalam memperbaiki mutu layanan
\end{abstract}

Kata kunci: kualitas, jasa perbankan, BRI Klaten, servqual

\begin{abstract}
This research aims at investigating external people satisfaction in public bank services, BRI office at Widya Dharma University of Klaten, 104 people are chosen as samples with convenience sample. Quantitative tests were carried out in the form of validity, reliability and Servqual confirmation tests. The result shows that most servqual model factors are: tangibility, reliability, assurance, responsiveness, empathy is less satisfying than it should be with average -57.27, and the dimensions of reliability have the biggest different value with -65.50 poin.
\end{abstract}

Keywords: quality, banking services, BRI Klaten, servqual

\section{PENDAHULUAN}

Kualitas dan pelanggan merupakan dua faktor utama bagi institusi bisnis. Kualitas yang baik cenderung akan diikuti dengan terbentuknya loyalitas pelanggan. Organisasi bisnis dan nir-laba harus selalu melakukan perbaikan kualitas untuk memenuhi keinginan dan harapan pelanggan. Organisasi harus terus berupaya agar harapan pelanggan bisa terpenuhi atau bahkan terlampaui (AlJazzazi, Sultan, 2017).

Dalam rangka membangun kualitas yang mengarah pada terbentuknya loyalitas pelanggan, organisasi harus bisa memahami siapa pelanggan mereka. Pelanggan bagi organisasi terbagi menjadi dua, yakni pelanggan eksternal dan pelanggan internal.

Pelanggan eksternal bagi PT Bank BRI adalah mereka yang menerima layanan jasa perbankan beserta atribut yang menyertainya, dalam skala yang lebih luas adalah mereka yang menjadi nasabah PT Bank BRI Kantor kas Unwidha.

Pelanggan internal adalah mereka yang menjadi bagian dari penyelenggara jasa layanan perbankan dan sekaligus juga 
menjalankan kebijakan yang ditetapkan manajemen dan organisasi, di dalam penelitian ini, kategori pelanggan internal adalah pegawai operasional bank, teknisi dan pegawai non operasional PT Bank BRI kantor Kas Unwidha.

Kepuasan nasabah adalah suatu keadaan dimana keinginan, harapan dan kebutuhan nasabah bisa dipenuhi oleh institusi penyelenggara. Suatu layanan memiliki hasil memuaskan apabila bisa memenuhi kebutuhan, keinginan dan harapan nasabah.

Ada beberapa faktor yang bisa dipertimbangkan oleh nasabah dalam menilai suatu mutu layanan antara lain: ketepatan waktu, dapat dipercaya, kemampuan teknis, serta harga yang sepadan dengan layanan yang diberikan. Berdasarkan faktor-faktor tersebut, nasabah dapat menilai tingkat kepuasan yang mereka terima dari jasa spesifik yang diberikan, serta tingkat kepercayaan mereka terhadap kemampuan pemberi layanan.

Kaushik (2013) meneliti bahwa kualitas layanan berpengaruh terhadap motivasi pembelian serta dimensi loyalitas merupakan faktor paling signifikan dalam mutu layanan. Terdapat beberapa dimensi antara lain tangibles, behavior dan convenience serta empat variabel lain yang juga relevan untuk sektor perbankan meliputi attitude, competence, tangibles dan convenience. Kepuasan nasabah merupakan elemen paling penting untuk menarik dan memelihara loyalitas pelanggan khususnya di sektor perbankan (Ennew et al. 2015).

Untuk mengukur mutu layanan jasa perbankan, perlu dilakukan pengukuran kepuasan layanan nasabah. Pada saat ini ditemukan persepsi masyarakat bahwa mutu layanan bank bank besar di Indonesia terutama Bank BUMN mengalami penurunan antara lain lamanya waktu antrean nasabah yang membutuhkan penyelesaian layanan kasir, teknologi pembayaran sering mengalami gangguan serta beaya layanan yang ditarik berupa fee base income semakin mahal. Dari gambaran di atas, diambil rumusan masalah utama: "Apakah layanan jasa perbankan oleh Bank BRI kantor kas Unwidha belum memuaskan nasabah?"

\section{LANDASAN TEORI Konsep Jasa}

Jasa adalah berbagai tindakan atau kinerja yang ditawarkan suatu pihak kepada pihak lain yang pada dasarnya tidak dapat dilihat dan tidak menghasilkan hak milik. Produknya bisa terkait dengan sebuah produk fisik maupun tidak.

Menurut Kotler (2018), jasa memiliki empat ciri utama: Intangibility, jasa bersifat tidak nyata. Untuk mengurangi ketidakpastian, pembeli akan mencari tanda atau bukti dari mutu jasa tersebut. Mereka mengambil kesimpulan mengenai mutu jasa dari tempat, orang, peralatan, bahan komunikasi, simbol-simbol, pihak refensi serta harga yang mereka lihat. Inseparability, jasa dapat diproduksi secara khusus dan dikonsumsi pada waktu bersamaan pada kondisi tertentu. Variability, jasa bisa beragam, karena sangat tergantung kepada siapa yang menyediakan jasa dan kapan, dimana jasa tersebut bisa disediakan Perishability, jasa tidak dapat disimpan. Suatu kondisi tidak tahan lama dari jasa bukanlah masalah jika permintaannya stabil.

\section{Servqual Model}

Riset yang berhubungan dengan pengukuran kepuasan pelanggan dari layanan yang diterima, mengukur derajat kepuasan dan menganalisis kemungkinan adanya berbagai kesenjangansebagai akibat dari selisih antara expectation service dengan perceived service, telah 
dilakukan oleh Parasuraman et.al (1991). Parasuraman mengembangkan dimensi servqual dalam lima dimensi berupa apabila dilakukan pada kantor layanan bank berupa: tangibles, penekanan pada kualitas penampilan fisik seperti gedung bank, layout ruang layanan, fasilitas AC bank, komputer kantor dan kecepatan sistem perangkat lunak serta warna gedung yang menjadi ciri khas kantor bank, Reliability, kemampuan memberikan layanan sesuai yang dijanjikan, seperti proses kredit cepat, murah dan efisien apakah benar sesuai dalam promosi bank, Responsivenes, keinginan untuk cepat tanggap dalam membantu nasabah dan memberikan layanan sebaik mungkin. Assurance, pengetahuan dan kesopansantunan para pegawai BRI, kemampuan mereka untuk menumbuhkan rasa percaya nasabah pada institusi serta Emphaty, perhatian tulus yang diberikan kepada nasabah. Pegawai bank memiliki rasa empati apabila mampu memahami rasa sebagai nasabah yang memerlukan pertolongan atau layanan segera

\section{METODE PENELITIAN Metode Pengumpulan Data Riset}

Metode survei digunakan dalam riset ini, yaitu mencari informasi secara langsung dari responden utama. Menurut Singarimbun (1985) metode survei adalah suatu riset yang mengambil sampel dari populasi sasaran dengan menggunakan kuesioner sebagai alat pengumpul data utama.

\section{Data yang digunakan}

Data primer digunakan sebagai data yang diperoleh secara langsung dari nasabah Bank BRI Kantor Kas Unwidha dimana mereka memiliki cukup pemahaman terhadap mutu layanan dari obyek yang diteliti.
Data sekunder juga diperlukan dalam riset berupa data dari sumber-sumber kepustakaan, catatan atau arsip institusi serta sumber lain yang berkaitan dengan penelitian.

\section{Teknik Pengumpulan Data}

Wawancara terhadap nasabah BRI Kantor Kas Unwidha dilakukan untuk memperoleh hal-hal yang berkaitan dengan gambaran umum BRI serta kepada pihak pegawai BRI terkait perencanaan strategi yang telah dilakukan.

Sebagai upaya memperoleh informasi utama dari nasabah, peneliti menyebarkan kuesioner secara acak terhadap nasabah bank yang telah mendapatkan layanan jasa perbankan di BRI Klaten kantor Kas Unwidha.

Studi Pustaka dilakukan untuk memperoleh data-data pendukung relevan yang diperlukan dalam riset.

\section{Metode Pengambilan Data}

Tidak semua individu dalam populasi diteliti karena keterbatasan waktu, akses dan biaya. Untuk itu digunakan metode sampling dengan berbagai cara sebagai berikut:

\section{Populasi}

Populasi adalah seluruh dari jumlah unit analisis yang ciri-cirinya bisa diduga. Dimaksud populasi dalam penelitian ini adalah seluruh nasabah Bank BRI Klaten Kantor Kas Unwidha.

\section{Teknik Pengambilan Sampel}

Responden yang dipakai dalam penelitian sejumlah 104 orang nasabah secara purposive sampling. Kriteria responden yang diambil sampel dalam penelitian adalah individu yang telah dewasa, dengan anggapan responden telah memiliki pengetahuan yang memadai dalam menilai 
bagaimana kualitas layanan yang diberikan Bank BRI Klaten kantor Kas Unwidha.

\section{Metode Analisis Data Uji Validitas dan Reliabilitas}

Uji validitas dilakukan untuk mengukur sejauh mana ketepatan dan kecermatan atribut, kuesioner dapat menjalankan fungsi sebagai alat ukur. Alat ukur dikatakan sahih atau valid apabila mampu mengukur apa yang ingin diukur. Dalam riset ini hasil pengukuran yang diperoleh cermat. Uji ini dilakukan dengan menggunakan metode Pearson product moment serta koreksi dilakukan melalui metode korelasi Part whole ( Sekaran, 2013).

Uji reliabilitas dilakukan guna mengukur sejauh mana alat ukur mampu melakukan pengukuran secara konsisten. Alat ukur dikategorikan handal (reliabel) jika hasil pengukuran memberikan data yang sama apabila diulang pada obyek yang berbeda untuk waktu yang berbeda. Uji reliabilitas dilakukan dengan metode Hoyt serta menggunakan alat bantu komputer program SPSS 21.

\section{Uji Konfirmasi Mutu Layanan}

Uji konfirmasi mutu layanan Bank BRI kantor kas Unwidha dilakukan dengan menggunakan kesenjangan ke-5 Servqual melalui metode Weighted ServQual Cronin Taylor, 1992) :

\section{I kj $=\sum(P$ ij-E ij)}

$\mathrm{I} \mathrm{kj}=$ konfirmasi terhadap objek $\mathrm{j}$

I $\mathrm{kj}<0=$ konfirmasi nasabah tidak puas

$\mathrm{I} \mathrm{kjb} \geq 0=$ konfirmasi nasabah puas

$P \mathrm{ij}=$ kinerja dari atribut $\mathrm{i}$ objek $\mathrm{j}$

$E \mathrm{ij}=$ harapan dari atribut $\mathrm{i}$ objek $\mathrm{j}$

\section{HASIL RISET DAN PEMBAHASAN Uji pra Survei Keandalan Kuesioner}

Agar penelitian berhasil secara optimal maka dilakukan pra-survei, kajian pustaka dan konsultasi kepada pihak terkait untuk memperoleh gambaran atribut apa yang sebaiknya diukur dalam dimensi mutu layanan. Dari hasil pra-survei diperoleh atribut-atribut yang dikategorikan dalam 15 item pertanyaan mutu layanan dimana: 5 item merupakan bukti fisik, 3 item dimensi keandalan, 2 item dimensi daya tanggap, 2 item dimensi jaminan serta 3 item dimensi empati. Kelima dimensi kemudian disusun menjadi pernyataanpernyataan yang mudah dipahami oleh nasabah Bank BRI Klaten Kantor Kas Unwidha

\section{Karakteristik Responden}

Karakteristik responden digunakan untuk melihat profil responden dalam penelitian. Dari temuan riset kategori responden berdasarkan jenis kelamin mayoritas adalah perempuan sehingga bagi nasabah Bank BRI Klaten kantor Kas Unwidha yang aktif ditemui saat riset nasabah wanita.

Kategori responden penelitian ditinjau berdasarkan umur diperoleh bahwa usia nasabah merupakan usia muda dan produktif, sehingga bisa disimpulkan bagi BRI peningkatan kualitas layanan bagi mereka yang berusia muda dan produktif patut diperhatikan sebagai faktor utama.

Dari komposisi responden berdasarkan pekerjaan mayoritas nasabah berprofesi sebagai buruh dan swasta, disimpulkan bahwa profesi tersebut masih memilih Bank BRI sebagai bank idola wong cilik dibandingkan Bank di tempat lain

\section{Uji Model Kuantitatif}

Kesungguhan dan keseriusan responden dalam menjawab pertanyaan merupakan esensi dari metode survai. Karena 
Praxis : Jurnal Sains, Teknologi, Masyarakat dan Jejaring | Vol. 3 | No. 2 | Maret 2021

keabsahan suatu hasil penelitian sangat ditentukan oleh alat ukur yang digunakan dalam proses pengumpulan data. Jika data yang diperoleh tidak valid atau tidak akurat maka hasil penelitian tidak akan dapat menggambarkan keadaan yang sebenarnya. Sehingga perlu dilakukan uji validitas dan reliabilitas.

\section{Uji Validitas}

Suatu skala pengukuran dikatakan valid apabila skala tersebut mampu mengukur apa yang seharusnya diukur. Misalnya skala nominal yang bersifat non parametrik digunakan untuk mengukur variabel nominal, bukan untuk mengukur variabel interval yang bersifat parametrik. Untuk menghitung validitas suatu kuesioner, digunakan teknik korelasi yang dibandingkan antara nilai skor dengan tabel. Adapun kuantifikasi 15 item pertanyaan uji validitas tertuang dalam tabel 1

Tabel 1

\section{Uji validitas butir}

\begin{tabular}{llll}
\hline Butir & Rxy & \multicolumn{2}{c}{ Rtabel Status } \\
\hline E1 & 0.625 & 0.374 & valid \\
E2 & 0.545 & 0.374 & valid \\
E3 & 0.498 & 0.374 & valid \\
E4 & 0.457 & 0.374 & valid \\
E5 & 0.442 & 0.374 & valid \\
E6 & 0.598 & 0.374 & valid \\
E7 & 0.572 & 0.374 & valid \\
E8 & 0.529 & 0.374 & valid \\
E9 & 0.428 & 0.374 & valid \\
E10 & 0.587 & 0.374 & valid \\
E11 & 0.435 & 0.374 & valid
\end{tabular}

\begin{tabular}{|c|c|c|}
\hline E12 & 0.497 & 0.374 \\
\hline E13 & 0.622 & 0.374 \\
\hline E14 & 0.821 & 0.374 \\
\hline E15 & 0.595 & 0.374 \\
\hline P1 & 0.543 & 0.374 \\
\hline $\mathrm{P} 2$ & 0.567 & 0.374 \\
\hline P3 & 0.595 & 0.374 \\
\hline P4 & 0.688 & 0.374 \\
\hline P5 & 0.785 & 0.374 \\
\hline P6 & 0.867 & 0.374 \\
\hline P7 & 0.695 & 0.374 \\
\hline P8 & 0.739 & 0.374 \\
\hline P9 & 0.611 & 0.374 \\
\hline P10 & 0.577 & 0.374 \\
\hline P11 & 0.756 & 0.374 \\
\hline P12 & 0.765 & 0.374 \\
\hline P13 & 0.625 & 0.374 \\
\hline P14 & 0.654 & 0.374 \\
\hline P15 & 0.792 & 0.374 \\
\hline
\end{tabular}

Sumber: data primer responden 2019

Tahap awal riset diuji 30 jawaban responden dibandingkan $r$ tabel bisa disimpulkan bahwa semua butir dinyatakan sahih.

\section{Uji Reliabilitas}

Hasil riset dalam uji reliabilitas menunjukkan bahwa semua dimensi pada kedua faktor lebih besar dari nilai cronbach alpha yang disyaratkan yaitu 0.8. Kuantifikasi secara lengkap uji reliabilitas tertuang dalam tabel 2 
Praxis : Jurnal Sains, Teknologi, Masyarakat dan Jejaring | Vol. 3 | No. 2 | Maret 2021

Tabel 2

Uji reliabilitas butir

\begin{tabular}{ccc}
\hline Faktor cronbach alpha ca -syarat \\
Status \\
\\
\hline \multicolumn{4}{c}{0.8610 .8} \\
Harapan nasabah & 0.8 Handal Layanan diterima \\
0.925 & 0.8 & Handal \\
\hline
\end{tabular}

Sumber: data primer responden 2019

Dari tabel terlihat kedua dimensi lulus uji serta dinyatakan handal untuk digunakan dalam tahap uji selanjutnya (Field, Meile, 2008)

\section{Uji Model ServQual}

Untuk menguji tingkat konfirmasi nasabah BRI Klaten Klaten Kantor Kas Unwidha digunakan rumus Weighted Servqual (Cronin, Taylor, 1992). Dari hasil kuantitatif riset diperoleh total nilai konfirmasi nasabah dari mutu layanan Bank BRI Klaten Kantor Kas Unwidha sebesar - 57.27.

Nilai konfirmasi maksimum atau minimum dengan jumlah responden sebanyak 104 nasabah dari data primer diperoleh angka:

$$
\text { Ikj } \max =416 \text { serta Ikj } \min =-416
$$

Nilai konfirmasi maksimum bisa dicapai oleh nasabah dengan asumsi bahwa nasabah memiliki harapan minimal terhadap mutu layanan yang akan diterima dan merasakan kinerja aktual yang maksimum terhadap mutu layanan yang diterima. Demikian sebaliknya, nilai konfirmasi minimum yang dapat dicapai nasabah diasumsikan bahwa nasabah memiliki harapan maksimum terhadap mutu layanan yang diterima, tetapi kenyataannya merasakan kinerja aktual minimum atas mutu layanan yang diterima.
Dalam perhitungan kuantitatif data primer, diperoleh nilai konfirmasi nasabah terhadap Bank BRI Klaten kantor Kas Unwidha memiliki interval sebesar 832, angka tersebut dibagi dalam 4 skala tingkat konfirmasi: sangat tidak puas, tidak puas, puas dan sangat puas, menurut preferensi nasabah sehingga didapat adanya pembagian range diperoleh nilai sebesar 208 poin.

Dari gambar 1 diperoleh data konfirmasi nasabah terhadap mutu layanan Bank BRI Kantor Kas Unwidha dalam suatu interval berikut:

\section{Sangat tidak puasTidak puasNetral Puas Sangat puas}

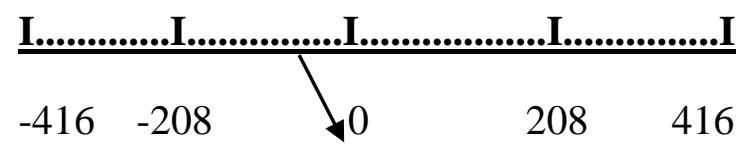

Konfirmasi nasabah dari mutu layanan BRI (-57.27)

\section{Gambar 1 \\ Konfirmasi nasabah mutu layanan (sumber: Data primer riset 2019)}

Gambar diatas disimpulkan bahwa nilai konfirmasi nasabah terhadap mutu layanan Bank BRI Klaten sebesar -57. 27 berada pada interval antara 0 sampai - 208 dengan kategori tidak puas. Standar minimal yang harus dicapai untuk memperoleh tingkat kepuasan layanan apabila nilai konfirmasi mencapai nilai sama dengan 0 atau lebih (konfirmasi $\geq 0$ ). Dari hasil riset diperoleh simpulan kepuasan nasabah dari mutu layanan Bank BRI Kantor Kas Unwidha belum tercapai.

Setelah diperoleh uji konfirmasi secara menyeluruh, diurai kesenjangan masingmasing dimensi mutu layanan meliputi dimensi bukti fisik, keandalan, daya tanggap, jaminan dan empati. Dari hasil riset diperoleh data dimensi keandalan memiliki nilai kesenjangan terbesar senilai -65.50, secara berturut-turut diikuti 
dimensi daya tanggap sebesar -62.12, empati sebesar -57.36, dimensi bukti fisik sebesar -57 dan terakhir dimensi jaminan sebesar -42.50. Dimensi keandalan berkaitan dengan penyediaan jasa dapat diandalkan. Penjelasan dari dimensi ini apakah pihak BRI Klaten dalam menangani masalah, telah menyampaikan jasa secara benar semenjak nasabah datang dan menyimpan catatan/ dokumen bank layanan transfer tanpa kesalahan sesuai standar dan prosedur.

Dalam dimensi keandalan dapat diukur pula bagaimana penyelesaian keluhan nasabah apakah bersifat cepat, akurat dalam melayani pendaftaran, registrasi nasabah dalam kondisi mendesak jika terjadi error bisa cepat dan tepat waktu sesuai janji. Bagaimana penyelesaian masalah terkait keandalan teknologi ATM serta keandalan perangkat perbankan lain. Dimensi yang memiliki nilai kesenjangan terbesar harus diprioritaskan dalam perbaikan mutu layanan bank, kemudian beralih pada prioritas dimensi berikutnya. Dengan kata lain untuk meningkatkan kepuasan nasabah, pihak Bank BRI Klaten Kantor Kas Unwidha harus memrioritaskan peningkatan mutu layanan pada dimensi yang memiliki nilai kesenjangan terbesar.

Dimensi keandalan memiliki nilai kesenjangan terbesar. Hal ini bisa dilakukan analisis, saat ini PT Bank BRI merupakan bank paling dipercaya Pemerintah RI dalam menangani berbagai program unggulan terkait transaksi perbankan modern. Pemilihan Bank BRI dibanding bank BUMN lain karena pertimbangan PT Bank BRI merupakan bank terbesar dalam perolehan asset, memiliki paling banyak jaringan kantor cabang, kantor cabang pembantu dan kantor kas sehingga mampu menjangkau domisili seluruh lapisan masyarakat Indonesia. Peningkatan pesat jumlah nasabah serta berbagai program layanan yang diemban saat ini kurang diikuti dengan meningkatnya program kualitas layanan. Fenomena ini sejalan dengan penelitian Ajmal et al. (2018) yang meneliti bank negara terbesar di kota Karachi Pakistan, dimana meningkatnya mutu layanan pada dimensi Servqual menjadi tertinggal dengan meningkatnya volume aset dan jumlah nasabah yang semakin besar.

\section{PENUTUP Simpulan}

Setelah dilakukan pembahasan pada bab sebelumnya diurai simpulan sebagai berikut:

Standar yang harus dicapai untuk memperoleh tingkat kepuasan minimum apabila nilai konfirmasi mencapai nilai sama dengan nol atau positif. Hasil uji konfirmasi nasabah Bank BRI Klaten Kantor Kas Unwidha didapat nilai sebesar $-57,27$. Nilai konfirmasi minimum yang dapat dicapai oleh layanan BRI sebesar 416. Sedangkan nilai konfirmasi maksimum yang bisa dicapai sebesar 416 . Artinya, tingkat kepuasan dari mutu layanan yang dirasakan nasabah masih minus $14 \%$ dari tingkat kepuasan maksimum. Untuk mencapai tingkat kepuasan minimum, Pihak Bank BRI Kantor Kas Unwidha harus mampu menutup kesenjangan sebesar $14 \%$ dari kepuasan minimum tersebut. Hal ini bisa disimpulkan pihak Bank BRI Klaten kantor Kas Unwidha belum mampu memberikan kepuasan pada mutu layanan yang diharapkan.

Dari hasil uji kuantitatif nilai konfirmasi nasabah pada tiap dimensi, untuk mencapai tingkat kepuasan nasabah, pihak Bank BRI kantor Kas Unwidha dalam meningkatkan mutu layanan harus memrioritaskan pada dimensi yang memiliki nilai negatif terbesar, dilanjutkan pada nilai negatif berikutnya. 
Nilai konfirmasi kepuasan nasabah negatif menunjukkan Bank BRI Klaten kantor Kas Unwidha belum mampu memberikan mutu layanan sesuai harapan nasabah. Simpulan ini dapat muncul karena domisili nasabah di kota Klaten berada ditengah antara dua kota besar Yogyakarta dan Kota Solo. Nasabah bisa membandingkan mutu layanan Bank BRI dengan berbagai lembaga layanan perbankan unggulan di dua kota besar tersebut. Semakin meningkat kesejahteraan ekonomi nasabah mereka akan semakin melek teknologi sehingga mereka memiliki tuntutan tinggi terhadap otomatisasi layanan, keandalan teknologi serta semakin prima mutu layanan institusi keuangan.

\section{Saran}

Dari simpulan, saran yang bisa diberikan :

Bank BRI Klaten harus terus berupaya meningkatkan mutu layanan kepada nasabah, sistem reward dan punishment harus diberlakukan kepada tenaga profesional bank untuk mengejar tingginya tuntutan mutu layanan prima institusi keuangan

Pihak BRI Klaten secara periodik wajib mengadakan survai mutu layanan. Hal ini perlu dilakukan karena harapan akan mutu layanan selalu berubah terkait lingkungan, waktu dan kondisi persaingan.

Di sisi lain dengan adanya Pandemi Covid19 saat ini, di era kenormalan baru di masa mendatang nasabah semakin menuntut perubahan layanan perbankan secara modern melalui mobile banking, meningkatnya jaringan perbankan nir kantor, minimal kontak fisik dengan pihak lain serta otomatisasi perangkat yang didukung reliabelnya teknologi.

\section{DAFTAR PUSTAKA}

Al-Jazzazi, A., Sultan, P. (2017). Demographic Difference in Jordanian Bank Service Quality Perceptions. International Journal Bank Mark, 35 pp 275-297

Ajmal, H., Khan R., Fatima, M. (2018). Impact of Services Quality on Customer satisfaction in Banking Industry of Pakistan: A Case Study of Karachi. Journal of Social and Administrative Science. Vol 5 Issue 3 pp 219-238

Cronin, J.J., Taylor, S.A. (1992). Measuring Services Quality: a Reexaminations and Extension. The Journal Of Marketing, 56, pp 56-68

Ennew, C.T., Binks, M.R and Chiplin, B. (2015). Customer Satisfaction and Customer Retention: an Examination of Small Business and Their Banks in UK. In Proceeding of The Academy of marketing Science (AMS) Annual Confrence 9, pp188-192 Springer, Cham

Field, J.M., Meile, L.C. (2008). Supplier Relations and Supply Chain Perfomance in Financial Services Processes. International Journal Operation Production Management, 28 pp 185-206

Kaushik, M. (2013). Customer Oriented Organization: a Frame Work for Innovation. Journal of Business Strategy, 34 93), 49-56

Kotler, P. (2018). Marketing Management. 15 ed, Pearson Education Limited

Parasuraman, A., Berry, L.L, Zeithaml, V.A. (1991). Understanding Customer Expectations of Services. Sloan Management Review, 32 pp 39-48

Sekaran, U., Bougie, R. (2013). Research Methods for Business: a Skill Building Approach. New Jersey: John Willey and Sons

Singarimbun, M., Effendi, S. (1985) Metode Penelitian Survey. Jakarta: LP3ES 